REVISTA X, Curitiba, volume 13, n.2,p.15-33, 2018.

\title{
DESAFIOS NA DOCÊNCIA DE LI EM ESCOLAS PÚBLICAS: PERCEPÇÕES E VIVÊNCIAS NAS NARRATIVAS DE PROFESSORES
}

Challenges of teaching English in public schools: perceptions and experiences in teachers' narratives

Míriam Rabelo GONTIJO (UEMG) ${ }^{1}$

RESUMO: Este artigo buscou compreender o mal-estar vivenciado pelos professores de língua inglesa, por meio da análise de seus relatos sobre a percepção acerca de seu próprio trabalho em escolas públicas de Divinópolis - MG. O Objetivo principal do estudo foi analisar as vivências dos professores e o impacto dessas experiências em sua vida pessoal e profissional. Para a realização da pesquisa utilizou-se de uma estratégia de pesquisa biográfica, as Histórias de Vida, em que cinco professores que trabalham com o ensino da LI foram convidados a falar sobre suas percepções. $\mathrm{O}$ tratamento dos dados se deu pela Análise de Conteúdo. Os resultados mostraram que os professores se sentem desvalorizados, tanto pela indisciplina e falta de interesse dos alunos, como pela falta de amparo e clareza dos documentos oficiais que regem o ensino da LI.

PALAVRAS-CHAVE: Percepções; Docentes; Mal-estar; Escola Pública.

ABSTRACT: This article sought to understand the uneasiness experienced by English teachers through an analysis based on their reports over the perception they have about their own work in public schools located in Divinópolis - MG. The main objective of the study was to analyze teachers' experiences and the impact of those experiences on their personal and professional lives. In order to carry out the research, the History of Life method was used, in which five teachers were invited to talk about their perceptions. The data analysis was conducted by Content Analysis. The results showed that teachers feel devalued, due to students' lack of discipline and lack of interest, as well as the lack of support and clarity of the official documents concerning English teaching.

KEYWORDS: Perceptions; Uneasiness; Teachers; Public schools

\section{INTRODUÇÃO}

Este estudo analisa o ensino de língua inglesa em algumas escolas públicas situadas na cidade de Divinópolis - MG e os impactos gerados na vida dos docentes dessa disciplina nessas escolas, causados pelas frustrações cotidianas oriundas das tentativas frustradas de se ensinar uma nova língua em um ambiente onde impera a ideia

\footnotetext{
${ }^{1}$ Professora na Universidade do Estado de Minas Gerais (UEMG), Departamento de Letras, área de ensino de Língua Estrangeira (Inglês). Doutoranda no Programa de Pós-Graduação em Estudos da Linguagem do Cefet-MG.
} 
REVISTA X, Curitiba, volume 13, n.2,p.15-33, 2018.

de que não se aprende inglês em escolas públicas (BARCELOS, 2006). Ensinar LI, principalmente em escolas públicas, tem sido um desafio para os profissionais que atuam na área; por isso, faz-se necessário aprofundar os conhecimentos sobre as questões relacionadas ao processo de ensino e aprendizagem dessa língua. O professor de LI tem um importante papel na formação do aluno e, apesar de toda a sua relevância dentro da sociedade, tem se tornado evidente sua desvalorização (MICCOLI, 2006).

Muitas são as dificuldades encontradas pelo docente em sua atuação. Os problemas vão desde a falta de preparação do profissional, perpassando a carência de material didático e a carga horária insuficiente, até a falta de estrutura das escolas para receberem os alunos para que os docentes consigam colocar em prática metodologias de ensino significativas. Essas questões têm impactado direta e indiretamente a qualidade do ensino e aprendizagem desta língua, bem como a vida pessoal e profissional do docente, que se sente frustrado diante da não eficiência de seu trabalho (ZOLNIER; MICCOLI, 2009).

Assim, embora alguns estudos, como o de Arruda (2014) afirmem que é possível propiciar experiências bem-sucedidas para a aprendizagem de LI nas escolas públicas, observa-se que nas práticas educativas, muitas ações desenvolvidas pelos professores acabam por não gerar os resultados esperados, fator que desencadeia uma série de consequências de caráter profissional e pessoal no educador. Dessa forma, em face do contexto apresentado, este estudo indaga: como o professor percebe o ensino de LI na educação básica pública e como a ineficiência de muitas de suas práticas educacionais impactam sua vida pessoal e profissional?

O objetivo geral do estudo é discutir sobre as vivências enfrentadas pelos professores de LI que atuam em escolas públicas, na intenção de verificar qual percepção eles carregam sobre o seu próprio trabalho. Busca-se ainda, avaliar os impactos de suas experiências em sua vida pessoal e profissional.

Este estudo mostra sua relevância por discutir o assunto trazendo a participação e as experiências do próprio professor, sujeito essencial para o processo de ensino e aprendizagem no contexto da educação básica pública. O mal-estar docente, expressão utilizada por Esteves (1999) para definir que algo não vai bem com a saúde do professor devido às suas condições laborais, precisa ser amplamente debatido para que propostas de intervenções sejam feitas em prol de um ensino público de qualidade e para melhorias na qualidade de vida docente. 
REVISTA X, Curitiba, volume 13, n.2,p.15-33, 2018.

\section{FUNDAMENTAÇÃO TEÓRICA}

Primeiramente, na seção 1, foi feita uma análise sobre as políticas que definem e direcionam o ensino de LI na educação básica pública. Na seção 2, foram expostos estudos que mostram o cotidiano docente, relatando os principais motivos que levam os professores de LI de escolas públicas a terem uma situação de trabalho angustiante. $\mathrm{Na}$ mesma seção, buscou-se discutir também a qualidade de vida de trabalho dos docentes de LI.

\section{Políticas para o ensino de LI no Brasil}

Dentre os regulamentos que regem o ensino de segunda língua no Brasil, encontram-se diversas instâncias. Duas delas, principais e decisórias, articulam as normas para a Educação Básica brasileira, como a Lei de Diretrizes e Bases - LDB (BRASIL, 1996) e os Parâmetros Curriculares Nacionais - PCNs - (BRASIL, 1998), que agem em esfera federal, por meio da Constituição Federal. Documentos mais recentes, como o PCN - ensino médio (2000), OCEM (2006) e a BNCC (2017) também são importantes para se compreender a trajetória do ensino de língua estrangeira nos últimos anos.

A LDB (BRASIL, 1996) reafirma o direito à educação, que deve ser garantido pela Constituição Federal. A lei estabelece princípios da educação e deveres do Estado no que tange à educação escolar pública. $\mathrm{O}$ documento traz a diretriz de se ofertar a disciplina de língua inglesa a partir do sexto ano do ensino fundamental. Para alguns pesquisadores, como Perrisse (2004) essa oferta é considerada tardia, por atrasar a vivência dos alunos em uma língua estrangeira.

Os Parâmetros Curriculares Nacionais - PCNs - (BRASIL, 1998), salientam que as línguas estrangeiras se tornaram uma parte integrante e indissociável do conjunto de conhecimentos que permitem ao estudante uma aproximação das diferentes culturas e, consequentemente, propiciam sua integração num mundo novo e globalizado. Assim, diante deste novo milênio que se configura pelo avanço das tecnologias, os PCNs ressaltam a importância da aprendizagem da LI como língua estrangeira, considerada, nos documentos oficiais, como uma linguagem universal, capaz de promover a integração entre povos. É importante ressaltar que esta é a visão exposta nos documentos oficiais e não é objetivo deste estudo o aprofundamento de discussões sobre a posição hegemônica da língua em questão. 
REVISTA X, Curitiba, volume 13, n.2, p.15-33, 2018.

No entanto, os PCNs de língua estrangeira do ensino fundamental priorizam uma, dentre as quatro habilidades; a leitura, pregando que poucas pessoas utilizam a LI em sua forma oral, mesmo em grandes centros urbanos. As outras habilidades, segundo o documento, embora possam ser trabalhadas, não devem ser objeto de atenção dos professores e alunos.

Rocha (2017, p. 1670), em análise sobre tal documento, dentre diversas críticas, expõe que em determinadas partes do texto as informações são contraditórias em relação à situação dos brasileiros perante a língua inglesa, como quando afirma que o Brasil é um país multilíngue e, logo após, classifica o país como essencialmente monolíngue.

Além disso, o autor pontua que os PCNs apontam as situações vivenciadas por professores e alunos em escolas públicas - como salas lotadas, falta de recursos, e carga horária reduzida - como fatores naturais. Na visão do autor, é como se essas situações precárias "estivessem dadas de uma vez por todas, como se alguma força se abatesse irremediavelmente sobre as aulas de línguas estrangeiras".

Ademais, não se pode ignorar o cenário atual, que é bem diferente do momento de redação dos PCNs. O desenvolvimento de todas as competências linguísticas, hoje, se faz necessário para maior inserção dos alunos em um contexto cultural, profissional, econômico e político que são diferentes da data de publicação dos PCNs. As línguas estrangeiras se fazem cada vez mais relevantes na vida das pessoas, sendo imprescindível incorporar as necessidades das novas gerações ao currículo escolar.

Naves e Vigna (2006) concordam que as competências esperadas do aprendiz não devem privilegiar apenas algumas habilidades, conforme estipulou-se nos PCNs. Espera-se que os alunos sejam capazes não somente de ler, mas também de falar, escrever e compreender a língua oral sem muitas dificuldades, já que, nos dias atuais, o mercado de trabalho exige cada vez mais uma formação integral do indivíduo.

Quanto ao PCN - Ensino Médio (BRASIL, 2000), Rocha (2017), em suas análises, encontra diversas inconsistências e incoerências textuais, que o levam a classificar o documento como confuso. O texto, nas palavras do autor, traz novamente as dificuldades encontradas pelos professores nas salas de aulas das escolas públicas e pontua que é devido a essas dificuldades que não se pode aplicar, efetivamente, as ideias mencionadas pelos textos legais às aulas. É como se a situação precária de infraestrutura e de recursos de muitas escolas fosse perene e imutável, e o ensino devesse ser discutido 
REVISTA X, Curitiba, volume 13, n.2,p.15-33, 2018.

utilizando como base essa realidade, ao invés de se propor mudanças que permitissem a diminuição dos problemas enfrentados no cotidiano escolar.

Nesse mesmo documento, o locutor aponta alguns fatores de desmotivação para a aprendizagem de inglês, como a hegemonia da língua inglesa, que deixa de lado outras línguas; a carência de formação de professores; além da escassez de livros didáticos motivadores. Por tudo isso, o documento pede que se reconsidere a concepção de ensino de língua estrangeira, avaliando a necessidade de se ensinar línguas diferentes, de acordo com o interesse comum da comunidade.

Segundo as Orientações Curriculares para o Ensino Médio - OCEM - (BRASIL, 2006), a última etapa da educação básica deve preparar o jovem para ser parte de uma sociedade complexa, que requer aprendizagem autônoma e contínua ao longo da vida; assim, a educação deve estar comprometida com o desenvolvimento total da pessoa para que sua atuação em sociedade seja responsável. O documento traz uma visão diferente do que se encontra nos PCNs acerca do ensino de LI ao focar as aulas não somente na leitura, mas na prática escrita e na comunicação oral contextualizada. $\mathrm{O}$ texto sugere a utilização das aulas de língua inglesa como espaço de promoção da consciência crítica dos alunos, de forma a contribuir para o exercício de sua cidadania, no sentido de transformá-lo em um agente de mudanças sociais.

Segundo a Base Nacional Comum Curricular - BNCC (BRASIL, 2017), aprovada para ao ensino fundamental, o ensino de inglês, na atualidade, deve voltar a ser obrigatório nas escolas. No documento, prescreve-se que sejam trabalhadas 88 habilidades nas aulas, divididas em cinco eixos: oralidade, escrita, conhecimentos linguísticos, gramaticais e dimensão cultural. Embora a BNCC seja um marco importante para que sejam implantadas estratégias que asseguram uma base de aprendizado comum aos estudantes, não se vê, nessa base, condições para que o docente consiga romper com o paradigma de se ensinar vocabulário e gramática. Além disso, não se discute, em suas páginas, a formação dos professores de LI no Brasil. Corre-se o risco, portanto da permanência de um ensino tecnicista, que não prepare os alunos para uma formação crítica, conforme o próprio documento propõe.

Assim, em face da realidade do mundo contemporâneo, globalizado e mais desenvolvido, o ensino e a aprendizagem de língua estrangeira não podem mais ser vistos e definidos como processos estáticos, limitados ao ato de ler e escrever. É preciso investir em mudanças que não deve estar somente em documentos oficiais, mas nas práticas docentes. Para isso, é preciso que o professor saiba como trabalhar e tenha a seu 
REVISTA X, Curitiba, volume 13, n.2,p.15-33, 2018.

dispor ferramentas e recursos, além de uma formação continuada que permita o desenvolvimento de suas próprias habilidades.

\section{Cotidiano do professor de li: vivência de percalços pessoais e profisssionais}

Kanikadan e Limongi-França (2006), em seus estudos, discutem a qualidade de vida de professores de LI, especificamente. Qualidade de vida, na visão das autoras, está associada a alguns fatores ligados ao bem-estar do trabalhador. Quanto à qualidade de vida no trabalho docente, as autoras consideraram em sua pesquisa as horas de trabalho dentro e fora da escola, além de fatores como: salário, interação com os demais colegas, eventos culturais, organização das atividades dos professores, entre outros. Segundo suas ideias, faz-se necessário estudar o professor de inglês separadamente dos docentes de outras áreas, pois existe uma série de fatores que trazem maior frustração a este profissional.

Nesse mesmo viés, Miccoli (2006) afirma que é preciso tratar dos assuntos referentes aos professores de LI a partir de suas experiências. Assim, percebe-se na literatura um crescimento de estudos desenvolvidos diretamente com docentes, o que indica um interesse e uma necessidade de se compreender o universo do professor de LI e suas particularidades. A autora (2006) aponta que as lacunas quanto aos conflitos existentes no ensino e aprendizagem de inglês em escolas regulares precisam ser preenchidas.

Os estudos de Dutra e Oliveira (2006) salientam que o contexto da escola regular é o que mais gera tensões, devido a fatores diversos, como turmas grandes, alunos desinteressados e um choque entre o desejo do professor e a expectativa do aluno. Nesse contexto, as autoras ponderam que a desmotivação gera grande indisciplina, prejudicando o professor e o grupo. Para contornar os conflitos e manter a disciplina, o professor investe em exercícios de escrita, em vez de adotar atividades comunicativas. Assim, ele tem a impressão de que mantém um controle maior dos alunos. Zolnier (2007) percebeu a mesma estratégia partindo dos professores que ela entrevistou em seus estudos.

Zolnier e Miccoli (2009) expõem, em seus estudos, narrativas de professoras do ensino regular que se sentem cansadas e em grande sofrimento profissional e pessoal, advindos das experiências em sala de aula. Essa agonia foi percebida por seus relatos, nos quais pontuaram exaustão e sintomas de doenças oriundas das condições de 
REVISTA X, Curitiba, volume 13, n.2,p.15-33, 2018.

trabalho e indisciplina e/ou indiferença dos alunos. As autoras ainda mencionam o fato de o ensino de inglês ser desvalorizado, já que as próprias escolas utilizam o horário de inglês para o desenvolvimento de outras atividades.

Entre as docentes que participaram da pesquisa de Zolnier e Miccoli (2009) nota-se que algumas acabaram por abandonar os cargos nas redes públicas de ensino devido a conflitos constantes em sala de aula. Na visão das docentes entrevistadas, tais conflitos são gerados, principalmente, por problemas relacionados à indisciplina, já que o comportamento dos discentes "foge ao padrão estipulado pelas pessoas, pela sociedade, pela nossa cultura, pela educação que a gente recebeu de berço", segundo palavras de Clara, uma das professoras (p.186). Segundo Rego (1996) o conceito de indisciplina não é estático, uniforme, nem universal. Ele está relacionado ao conjunto de valores e expectativas, que são variáveis ao longo da história, entre as diferentes culturas, mesmo que em uma mesma sociedade.

Para ilustrar, a entrevistada cita comportamentos como passar maquiagem dentro de sala; usar celulares constantemente para fins diversos, exceto para educativos; passar esmalte; escutar música; conversar paralelamente à aula; apresentar postura desrespeitosa na presença das professoras; apresentar desinteresse em executar as atividades propostas e em participar de atividades que envolviam o uso oral da língua. Nesse contexto, as docentes relataram sentir uma dificuldade constante em desenvolver um trabalho significativo.

Guia e Silva (2013) complementam a ideia da desvalorização ao afirmarem que há muitos anos o ensino da LI nas escolas públicas vem sendo desprestigiado, tanto pelos membros da comunidade escolar, como também pela sociedade, e afirma que os alunos, apesar de reconhecerem a importância do inglês, tratam o ensino da língua nas escolas públicas ora com desprezo, ora com indiferença, o que colabora para a indisciplina em sala de aula, aumentando as angústias do docente. As autoras relatam que as professoras pesquisadas apresentaram grande desconforto em trabalhar com o livro didático adotado pela escola e em lidar com seus temas transversais, que propunham discussões e atividades variadas, mas que apresentavam facilidade em utilizar a lousa e explicar gramática. No entanto, o estudo apontou que o método de trabalho proposto pelas docentes não era suficiente para que os alunos se sentissem interessados pelas aulas.

Por esse motivo, as autoras ressaltam a importância de os professores buscarem formas criativas e significativas de ensinar, com a utilização de diferentes estratégias 
REVISTA X, Curitiba, volume 13, n.2,p.15-33, 2018.

que despertem nos alunos interesse pela aprendizagem. Para isso, não se deve pensar somente no que ensinar, mas em como os alunos podem aprender melhor, em uma busca pelo despertar de sua vontade e curiosidade em conhecer a LI, já que muitos discentes não vão para a sala de aula interessados em aprender uma nova língua. Para isso, deve-se focar no que é significativo para os alunos daquela comunidade, já que os interesses diferem de acordo com os grupos para os quais se ensina.

As autoras pontuam em suas análises que certamente espera-se dos professores e das escolas uma boa formação dos alunos. No entanto, não se pode culpar esses sujeitos e instituições por todos os insucessos de aprendizagem, já que fatores como infraestrutura não pensada para o ensino e aprendizado de línguas, indisciplina discente, desconforto do professor em relação ao material didático e conteúdo denso que requer o conhecimento prévio de língua que os alunos ainda não possuem fazem parte da realidade cotidiana dessas escolas.

Paula (2015) e Marzari e Gehres (2015), por meio de suas ideias, também dialogam sobre os motivos que levam os professores a situações desgastantes em seu trabalho. Entre as razões, elas detectaram a falta de material didático adequado, o desinteresse demonstrado pelos alunos em relação à disciplina e a carga horária insuficiente para o ensino eficaz dos conteúdos. Outro problema em relação ao ensino de línguas estrangeiras na educação básica é o fato de muitos professores não estarem ou não se sentirem devidamente qualificados para ensinarem determinado idioma. Ainda assim, poucos são os docentes que buscam uma educação continuada, pois se encontram num ambiente onde não há grandes perspectivas de melhora, em seu ponto de vista.

Percebe-se, por meio dos estudos citados nesta seção, que muitos desafios são enfrentados diariamente pelos professores de LI diante da desvalorização da profissão. A falta de reconhecimento e a precária situação de trabalho nas escolas inviabilizam o investimento na profissão e cooperam para a desmotivação do professor, que tende a perder prestígio diante dos docentes das demais matérias, causando-lhe vergonha e agonia. Todos estes fatores influenciam diretamente a atuação do professor em sala de aula. Muitos docentes, ao verem suas expectativas quanto à docência frustradas, revelam suas preocupações e dúvidas no tocante ao exercício da profissão e sua permanência nela. 
REVISTA X, Curitiba, volume 13, n.2, p.15-33, 2018.

Assim, é fato notório que as relações entre escola, estudantes e professores de inglês encontram-se abaladas e carentes de maiores estudos que possam refletir sobre a temática, em busca de soluções para o problema.

\section{METODOLOGIA}

Para melhor desenvolver este estudo, realizou-se uma pesquisa de natureza qualitativa. Essa abordagem se faz pertinente neste estudo por lidar com uma realidade não mensurável, que compreende uma gama de significados, aspirações, motivações, crenças, atitudes e valores, englobando um mergulho em um espaço profundo das relações, dos processos e dos fenômenos (GODOY, 1995).

Este estudo foi realizado por meio da análise de Histórias de Vida de docentes de LI de escolas públicas de Divinópolis, na tentativa de conhecer profundamente suas vivências e experiências. Neste estudo, entende-se História de Vida como uma estratégia de pesquisa que está incluída na abordagem biográfica. Essa estratégia referese a registros escritos, baseados em narrativas pessoais de partes importantes de uma vida, coletadas por meio de conversas ou entrevistas (DENZIN, 1989).

Segundo Queiroz (1988), as Histórias de Vida permitem a utilização de técnicas para revelar o cotidiano, as opiniões, valores e o tipo de relacionamento entre indivíduos; através dos dados assim obtidos, torna-se possível construir um primeiro diagnóstico dos processos em curso.

Denzin (1989) completa que, para compreender as histórias, é necessário adentrar o universo dos participantes, buscando uma análise grupal, cultural, ideológica e histórica, já que as experiências pessoais derivam desse contexto. A geração de dados se deu por meio de entrevista narrativa, realizada em encontros individuais com os professores.

Para isso, cada docente foi convidado a falar livremente sobre sua trajetória profissional, relatando suas conquistas, vivências e percalços. Os professores trabalham em escolas diferentes e foram selecionados após sugestão de um coordenador de uma escola pública que, por ser também professor de língua inglesa, conhecia profissionais de diversas escolas. O objetivo de se selecionar docentes de escolas diferentes, foi conhecer as vivências em ambientes variados. No entanto, percebeu-se que o discurso dos professores, mesmo sendo oriundos de escolas diferentes, se repetiam, o que fez com que a pesquisa parasse no quinto docente, já que, embora relatassem trajetórias 
REVISTA X, Curitiba, volume 13, n.2,p.15-33, 2018.

diferentes quanto à sua formação, apresentavam pontos similares quanto às suas vivências.

As falas dos docentes foram gravadas e transcritas. Todos os nomes originais foram trocados por fictícios, para a preservação de sua identidade; em seguida, realizouse a análise de conteúdo do material gerado. Segundo Moraes (1999), esse tipo de análise leva a descrições sistemáticas e qualitativas, que auxiliam no processo de interpretação, na tentativa de compreender os significados do que foi dito. Bardin (1979) define a análise de conteúdo como um grupo de técnicas para análise de comunicações. O objetivo é obter descrições de todo o conteúdo de mensagens, permitindo inferir o conhecimento referente a elas.

Por fim, alguns trechos das falas dos entrevistados foram selecionados e, em seguida, separados segundo as categorias que emergiram para as análises. Os trechos foram mantidos na íntegra para que fosse possível respeitar a forma de expressão de cada sujeito.

\section{SÍNTESE DOS RELATOS}

\section{Gabriela}

Gabriela tem 37 anos e formou-se em Letras pela Universidade de Itaúna há 16 anos. É pós-graduada em Inglês pela UFMG e trabalhou por dois anos como professora da rede pública até pedir exoneração por problemas relacionados ao estresse no trabalho. Ela expõe que a comemoração pela aprovação no concurso durou pouco, já que a realidade a que esteve exposta foi árdua. Hoje ela atua em cursinhos de idiomas e não pensa em retomar a seus trabalhos na rede pública. Em suas palavras, "no cursinho é possível ver o resultado do trabalho, diferentemente da escola onde atuei".

\section{Paula}

Paula tem 43 anos, graduou-se em Letras pelo INESP e tem pós-graduação em linguística aplicada em ensino de Português. Foi aluna de curso de idiomas, trabalhou como professora de Inglês e Português e prestou serviços de tradução por um longo período e morou na Alemanha o que contribuiu para seu conhecimento linguística. Ela trabalha na rede pública há 22 anos e diz que, em sua trajetória, já se importou muito com a indisciplina, mas que hoje já sabe lidar melhor com esses alunos, que ela conhece “de longe". Ela já tentou alguns projetos para trabalhar com número reduzidos de alunos 
REVISTA X, Curitiba, volume 13, n.2,p.15-33, 2018.

por sala nas aulas de inglês das escolas públicas e lamenta que o governo não permita esse tipo de autonomia às escolas. Embora ela descreva seu trabalho como desvalorizado, pelo fato de não ter reprovação de alunos, o que ocasiona indisciplina e desinteresse, ela diz que com o tempo, após uma ameaça vinda de um aluno, resolveu tentar estratégias para parar de sofrer com a indisciplina. Segunda a docente, "hoje, em minha sala, ninguém fica sem fazer nada!" Ela relata que aprendeu, com a maturidade, a resolver pendências escolares dentro da escola, e a não levar trabalho para casa, o que diminui seu cansaço. Ela diz que tenta trabalhar as quatro habilidades linguísticas em sala, mas enfrenta dificuldades devido à infraestrutura; portanto, dedica-se, na maior parte do tempo, ao desenvolvimento da leitura. Ela ainda pontua que tem uma boa parceria de trabalho com a direção, que permite que a docente trabalhe de forma livre

\section{Lucas}

Lucas tem 40 anos, é de Belo Horizonte, mas mora em Divinópolis há 23 anos, e graduou-se em Letras no ano de 2005; possui pós-graduação em Inglês - Língua, Ensino e Cultura. Em sua jornada de 12 anos de ensino na rede pública, ele classificou suas vivências como mais cansativas que satisfatórias, tanto pelas burocracias exigidas pelo cargo, como pela indisciplina dos alunos. Lucas se sente frustrado por não conseguir manter uma sequência no conteúdo ensinado em suas aulas, devido ao fato de sempre ter que retomar o conteúdo do zero, o que, em sua visão, indica uma falha no sistema de ensino.

\section{Jaqueline}

Jaqueline tem 35 anos, formada em Letras e tem pós-graduação em ensino de LI pela UFMG. Começou a trabalhar em cursinhos como professora de inglês e, posteriormente, foi trabalhar em escolas particulares até passar em um concurso e assumir o cargo como professora efetiva da rede pública de ensino. Jaqueline trabalha hoje em uma escola cujos alunos são classificados por ela como "extremamente carentes" e indisciplinados, fazendo com que o trabalho seja desgastante. No entanto, a professora diz que gosta de sua profissão e que realiza projetos interessantes na escola apesar das dificuldades enfrentadas.

\section{Alan}


REVISTA X, Curitiba, volume 13, n.2,p.15-33, 2018.

Alan tem 57 anos, se formou em Letras pelo INESP no ano de 2003, mas começou a exercer a profissão de professor de LI apenas em 2014, com o objetivo de complementar seu salário. Antes disso, atuava apenas como professor de português e nunca buscou formação continuada em inglês. Ele trabalha em duas escolas: em uma como professor de Inglês e em outra como supervisor. Ele enxerga o trabalho na rede pública como desgastante e desvalorizado e afirma que o baixo salário, a indisciplina e a falta de interesse dos alunos o fazem pensar em desistir de ser professor.

\section{ANÁLISE DOS RESULTADOS}

Durante a coleta dos relatos, algumas categorias emergiram de forma natural e comum aos sujeitos de pesquisa ao relatarem suas vivências enquanto professores de inglês de escolas públicas. Essas categorias foram, principalmente: 1) a desvalorização do professor e 2) a indisciplina dos alunos, que serão discutidas abaixo. Embora alguns professores tenham relatado terem aprendido a lidar com a indisciplina, ou a tentarem desenvolver projetos significativos, nenhuma história de sucesso emergiu neste estudo, embora sabe-se que elas existam e sejam discutidas em outros estudos, como de Arruda (2014).

Cabe, portanto, a este estudo, discutir os pontos fracos do ensino de LI nas escolas públicas pesquisadas, para que seja possível conhecê-los a fundo no intuito de pensar em melhorias possíveis.

\section{Desvalorização docente}

Para iniciar as análises quanto à desvalorização do professor de inglês, é importante lembrar as palavras de Guia e Silva (2013), que ressaltam o desprestígio que ocorre entre os professores de inglês, pelos demais membros da comunidade escolar e pela sociedade em geral. A desvalorização traz consigo um sentimento de inferioridade que o docente capta pelos demais professores, alunos e diretores. Tais sentimentos foram depreendidos nos relatos de todos os docentes, conforme ilustrado a seguir:

(...) Eu acho o inglês uma disciplina desvalorizada. Sobre a questão de tirar os alunos dos horários de inglês, isso sempre acontece, principalmente quando as minhas aulas são nos horários finais, aí quando tem algum evento na escola eles pedem meus horários para realizá-los durantes as minhas aulas (Paula). 
(...) $\mathrm{O}$ que mais acontece é eles marcarem atividades no meio da sua aula, não no meio; a verdade é que tomam todo o seu horário... isso não está certo... (Gabriela).

Paula e Gabriela mostram que se sentem inferiorizadas em relação às demais matérias, em especial ao descaso advindo não somente dos alunos, mas também da direção. Elas relatam que perdem uma parte dos seus horários - que já são insuficientes para o ensino da disciplina - para a escola realizar outras atividades. Isto faz com que elas se sintam inferiores ao demais professores, que têm sua carga horária respeitada.

Uma outra queixa relaciona-se às dificuldades que a escola tem para adquirir recursos tecnológicos, tão necessários para os professores, principalmente os de línguas, já que em muito podem contribuir para experiências de sucesso em sala de aula. Coelho (2005) afirma que há uma grande frustração por parte dos professores da rede pública causado pelo momento de crise política e financeira, o que abala e desestrutura o ensino e a vida do profissional. Para ilustrar a crise mencionada a autora cita Bohn (2003), que pontua que o ensino se vê empobrecido, com falta de recursos, falta de investimento e diversas escolas apresentam péssimas condições físicas. O ensino público, antes escolhido pela elite, passa a ser utilizado pela classe menos favorecida. Na atualidade, essa crise apresenta-se agravada e o investimento na educação é baixo e ineficiente (FRAGA, 2018).

Por tudo isso, os professores sentem-se desanimados e se vêem limitados diante das condições da sala de aula que encontram, como, por exemplo, o grande número de alunos por turma, o número reduzido de horas-aula semanais e a falta de material didático.

(...) a valorização da disciplina de LI é muito baixa, vivemos numa cultura onde o aluno já tem certeza de que o inglês não dá bomba, então, devido à hierarquia da nossa disciplina, eles colocam a Matemática e o Português no topo e as Línguas Estrangeiras estão num patamar baixo. Na escola pública ainda temos o problema de infraestrutura, falta de recursos e salas lotadas. Tudo isso nos deixa agoniados (Lucas).

Existe também um processo de desvalorização da docência, que se evidencia pela baixa remuneração, falta de reconhecimento da profissão e a precária situação de trabalho nas escolas, que agregam valores negativos e cooperam para a desmotivação do professor de LI, presente nas instituições de ensino regular. Observa-se este sentimento no trecho a seguir: 
muito, pois não vivo com apenas um cargo e, por ter dois, tenho um dia muito corrido e cansativo. Sinto-me cansado mesmo (Alan).

Tal realidade força o professor a assumir muitas aulas, em várias escolas diferentes, o que desmotiva e inviabiliza ao docente buscar o seu desenvolvimento profissional.

Diante das vivências analisadas acima, configura-se o sentimento docente como de indignação, que acarreta vários outros sentimentos similares, como o de inferioridade. Isso acaba por prejudicá-lo, trazendo desânimo e falta de interesse em buscar uma educação continuada. Assim, percebe-se a necessidade de uma interferência política e social para que possíveis melhorias possam ocorrer. Para tal, é necessário que a sociedade exija que lhe seja ofertada educação de qualidade e que professores tenham melhores condições de trabalho.

Além disso, é importante que as escolas tenham infraestrutura que permita o desenvolvimento de atividades significativas. Essa infraestrutura engloba tecnologias a serem utilizadas em sala de aula e ambiente institucional acolhedor, o que nem sempre poderá ser fornecido apenas por docentes, por seu alto custo. Por isso, é primordial que governantes reconheçam a importância do investimento na educação e lacem mão de recursos financeiros suficientes para fins didáticos. É preciso reconhecer que recursos tecnológicos e uma educação voltada para autonomia podem fazer diferença para a aprendizagem .

\section{Indisciplina dos alunos}

Paula (2015) afirma que, além das dificuldades relacionadas à aprendizagem da LI e desmotivação, deve-se observar também outros aspectos operacionais da atividade do ensino que os professores enfrentam, como as salas superlotadas, a indisciplina e a insegurança. Desses pontos, a indisciplina emergiu na fala de todos os sujeitos desta pesquisa, consagrando-se como um ponto crucial gerador de mal-estar nas vivências docentes.

(...) A disciplina em sala de aula é péssima; indisciplina é um ponto forte, porque os alunos não têm interesse (...) Às vezes tinha até medo de entrar na sala de aula (Gabriela).

(...) Eu acho uma falta de respeito quando você pede o aluno silêncio e tem que ficar esperando a boa vontade dele. É uma falta de respeito pelo meu trabalho (Jaqueline). 
Nestes trechos pode-se perceber o enorme desafio que os docentes enfrentam. Segundo Miccoli (2014), os estudantes têm noção da hierarquia em sala de aula, no entanto, o reconhecimento da autoridade do professor não garante o respeito de alguns alunos. O gerador da indisciplina, na opinião dos docentes, é o desinteresse, conforme ilustrado abaixo:

(...) quanto à sala de aula, é muito cansativo, porque você passa a maior parte do tempo chamando a atenção, os alunos demonstram total desinteresse. Acho que isso é cultural, sabe? Deixam o inglês de lado... (Lucas).

(...) Nós temos um sério problema de indisciplina em sala, ocasionado pelo desinteresse, por serem meninos carentes, tanto socialmente quanto emocionalmente, eles tentam chamar a atenção (Jaqueline).

(...) As salas de aulas são muito cheias, nem metade da turma demonstra interesse pelas aulas e manter a sala quieta é uma missão quase impossível (Alan).

O professor Alan relata, ainda, a dificuldade de manter a turma envolvida, ressaltando a superlotação das salas de aula. Ele complementa:

(...) quando saio daqui me sinto muito desgastado, sofro por pensar que terei de voltar no dia seguinte (Alan).

O relato ilustra como os professores concebem a indisciplina, compreendida como falta de atenção, descaso com o professor e conversas paralelas. Kanikadan e Limongi-França (2006) retratam a qualidade de vida dos professores que, segundo elas, está relacionada a diversos fatores, como as horas de trabalho dentro e fora da escola, a baixa remuneração e as condições precárias das escolas. Sobre isso, Paula desabafa:

(...) Já gostei muito de dar aulas, hoje está sendo uma tarefa muito árdua e cansativa, principalmente pela indisciplina e falta de interesse dos alunos. É muito trabalho dentro e fora da sala de aula (Jaqueline).

As experiências citadas demonstram como o professor de LI é tomado por sentimentos adversos desde o início de suas carreias. Há de se reconhecer, obviamente, que alguns desses problemas comungam com os de outras disciplinas, mas alguns são agravados no ensino de inglês, conforme apontaram Kanikadan e Limongi França (2006).

Em virtude dos resultados aqui descritos, a indisciplina em sala de aula está longe de ser um problema apenas comportamental, já que pode estar diretamente ligada a questões de natureza social, já que o aluno não percebe em seu cotidiano a 
REVISTA X, Curitiba, volume 13, n.2,p.15-33, 2018.

necessidade de saber uma nova língua, aliada à velha crença de que não se aprende inglês na escola, como aponta Barcelos (2006). Nesse contexto, não se pode deixar de citar outros fatores, como as práticas pedagógicas adotadas por muitos professores que tornam a aula desinteressante, além do currículo escolar que por vezes um papel marginal à disciplina de língua estrangeira (BRITISH COUNCIL, 2015).

Conclui-se, então, que as relações conflituosas entre professores e alunos, conforme definem Guia e Silva (2013) devem ser analisadas e trabalhadas para que incidentes relacionados à indisciplina possam ser evitados e para que o ensino evolua em qualidade. Compreender as necessidades reais dos estudantes em seu contexto de vida e estabelecer as bases do ensino no interesse do discente, podem contribuir para que o professor consiga exercer melhor sua profissão, diminuindo sua agonia no trabalho.

\section{CONSIDERAÇÕES FINAIS}

Este estudo objetivou, por meio das narrativas de Histórias de Vida, compreender como o professor percebe suas vivências ao ensinar a LI nas escolas públicas e como as diretrizes e as práticas educacionais contemporâneas impactam suas vidas pessoais e profissionais. Cinco docentes foram convidados a falar sobre suas vivências enquanto professores.

Quanto aos impactos causados ao docente pelo cotidiano em escolas públicas, nota-se uma angústia em sua vida profissional que invade sua vida pessoal. Esses sofrimentos partem do desrespeito por parte de diversos alunos, que consideram o ensino de inglês pouco importante. A falta de disciplina gerada pelo desinteresse provoca grande estresse, assim como o sentimento de inferioridade diante de seus colegas de trabalho das demais disciplinas. A consequência do peso da vida escolar tem refletido diretamente na vida pessoal deste profissional, que se sente cada vez mais cansado e angustiado com o seu trabalho.

Assim, observou-se, por meio dos relatos, que o professor percebe seu trabalho, de uma forma geral, como árduo e pesado, embora reconheça a importância da profissão. Os resultados apontaram que para haver uma melhoria nas condições de trabalho, as diretrizes e leis que regem o ensino precisam ser melhor discutidas conforme contexto atual, no que tange ao ensino da LI. Como a carga horária dispensada ao ensino de língua estrangeira é curta, práticas que levem os alunos a desenvolverem sua autonomia, além da utilização de aparatos tecnológicos pelos 
REVISTA X, Curitiba, volume 13, n.2,p.15-33, 2018.

professores, que funcionem como recursos para o desenvolvimento de atividades significativas, podem ser alternativas interessantes para uma mudança de cenário.

Para isso, há de se investir na educação por meio de melhorias em infraestrutura dos prédios institucionais; melhorias no currículo, no que tange às horas destinadas ao ensino de línguas estrangeiras e reconhecimento da importância dos docentes. Esse reconhecimento pode se dar não somente por um salário justo e benefícios, mas também por investimento em projetos de formação continuada que permitam que eles tenham condições de fazer um bom trabalho.

Almeja-se que os resultados desta pesquisa possam contribuir para novas reflexões, discussões e possíveis interferências no ambiente acadêmico, contribuindo para que ações governamentais e institucionais possam melhorar a vida dos professores e, consequentemente, a dos alunos, que precisam de motivação e de aulas melhores para se interessarem pelo Inglês. Ressalta-se, ainda, a importância de se investir em uma educação continuada para a melhoria da qualidade das aulas, melhores condições de trabalho e mais ações que possam valorizar o docente.

\section{REFERÊNCIAS}

ARRUDA, C. É preciso propiciar a aprendizagem de inglês na escola: experiências bem-sucedidas para investir em uma mudança de paradigma. [Tese de Doutorado]. UFMG, 2014.

BARCELOS, A. M. F. Cognição de professores e alunos: tendências recentes na pesquisa de crenças sobre ensino e aprendizagem de línguas. In: BARCELOS, A. M. F.; VIEIRA ABRAHÃO, M. H. (Org.). Crenças e ensino de línguas: foco no professor, no aluno e na formação de professores. Campinas: Pontes, 2006. p. 15-41

BARDIN, L. Análise de Conteúdo. Lisboa: Ed. 70, 1979.

BRASIL. LDB. Lei 9394/96 - Lei de Diretrizes e Bases da Educação Nacional. Brasília. DF. 1996.

Ministério da Educação. Parâmetros Curriculares Nacionais: Ensino Médio: Linguagens, códigos e suas tecnologias. Brasília: Secretaria de Educação Média e Tecnológica, 1999.

- Ministério da Educação. Secretaria de Educação Básica. Orientações Curriculares para o Ensino Médio: linguagens, códigos e suas tecnologias. Brasília: SEB/MEC, 2006. 
REVISTA X, Curitiba, volume 13, n.2,p.15-33, 2018.

- Ministério da Educação. Base Nacional Comum Curricular - versão atualizada. Brasília, DF, 2017.

- Secretaria de Educação Média e Tecnológica. Parâmetros curriculares nacionais (Ensino Médio) - Linguagens, Códigos e suas Tecnologias. Brasília, 2000.

BRITISH COUNCIL. O Ensino de Inglês na Educação Pública Brasileira: Elaborado com exclusividade para o British Council pelo Instituto de Pesquisas Plano CDE. 1. ed. São Paulo: 2015

COELHO, H. S. H. É possível aprender Inglês na escola? Crenças de professores $e$ alunos sobre o ensino de Inglês em escolas públicas. (Tese de Mestrado). UFMG, 2005.

DENZIN, N. K. The research act: a theoretical introduction to sociological methods. 3, ed. Englewood Cliffs NJ: Prentice Hall, 1989.

DUTRA, D. P. \& OLIVEIRA, S. B. Prática reflexiva: tensões instrucionais vivenciadas pelo professor de LI. In: BARCELOS, A.M.F. \& Abraão, M.H.V. (orgs.) Crenças e ensino de línguas: foco no professor, no aluno e na formação de professores. Campinas, SP: Pontes editores, 2006.

ESTEVES, J. M. O mal-estar docente; a sala de aula e a saúde dos professores. São Paulo: EDUSC. 1999.

GODOY, A. S. et al. Introdução à pesquisa qualitativa e suas possibilidades. Revista de Administração de empresas, v. 35, n. 2, p. 57-63. Mar./ Abr. 1995.

GUIA, M. P. C; SILVA, V. L. Um estudo de caso sobre o ensino e aprendizagem de LI na escola pública. UFMT. Boca da tribo. 2013.

KANIKADAN, A. Y. S.; LIMONGI FRANÇA, A. C. L. A construção de um instrumento de coleta de dados a partir do modelo de indicadores biopsicossocial e organizacional - BPSO - 96 e do modelo de competências do bem-estar - BEO, sobre gestão de qualidade de vida no trabalho. ReAd, 54.ed. V. 12, n. 6, nov-dez 2006.

MARZARI, G. Q.; GEHRES, W. B. S. Ensino de inglês na escola pública e suas possíveis dificuldades. Thaumazein, Santa Maria, v.7, n.14, p. 12-19, dezembro 20015.

MORAES, R.. Análise de conteúdo. Revista Educação, Porto Alegre, v. 22, n. 37, p. 732, 1999.

MICCOLI, L. Avaliação da aprendizagem de ILE: uma realidade que choca. Trabalhos em Lingüística Aplicada, Campinas, v. 45, n. 1, p. 103-118, 2006.

MICCOLI, L. S. Pesquisa experiencial em contextos de aprendizagem: uma abordagem em evolução. Campinas, SP: Pontes Editores, 2014.

NAVES, R. R.; VIGNA, D. D. Os Parâmetros Curriculares Nacionais e o ensino de Inglês no Brasil. Universidade Católica de Brasília. 2006. 
PAULA, L. G. Dificuldades inerentes ao processo de ensino e aprendizagem da LI: contribuições para a formação de professores de línguas. Enciclopédia Biosfera, Goiânia, v.11, n. 20; p. 910, 2015.

PÉRRISÉ, P. Crianças pequenas aprendem quantos idiomas simultâneos o ambiente lhes proporcionar. In: O bilingüismo na escola favorece ou prejudica aprendizagem? Pátio. Ano VIII, 31 ago/out, 2004.

QUEIROZ, M. I. P. de. Relatos orais: do "indizível" ao "dizível”. In: SIMSON, Olga M. V. Experimentos com histórias de vida: Itália-Brasil. São Paulo: Vértice, 1988.

REGO, T. C. R. A indisciplina e o processo educativo: uma análise na perspectiva Vygotskiana. In: AQUNIO, J. G. (org.) Indisciplina na escola: alternativas Teóricas e Práticas. São Paulo: Summus,1996.

ROCHA, Décio. Descompassos da legislação brasileira sobre o trabalho do professor de línguas estrangeiras no ensino básico. Fórum Linguístico (Online), v. 14, p. 1667-1681, 2017.

ZOLNIER, M. C. A. P. LI: expectativas e crenças de alunos e de uma professora do ensino fundamental [Tese de doutorado] - Campinas, SP, 2007.

ZOLNIER, M. C. A. P.; MICCOLI, L. S. 2009. O desafio de ensinar inglês: experiências de conflitos, frustrações e indisciplina. Revista do Gel, v. 6, n. 2, p. 175206, 2009. 